Article

\title{
Neospora caninum: Differential Proteome of Multinucleated Complexes Induced by the Bumped Kinase Inhibitor BKI-1294
}

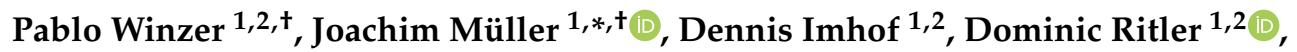 \\ Anne-Christine Uldry ${ }^{3}$, Sophie Braga-Lagache ${ }^{3}$, Manfred Heller ${ }^{3}$, Kayode K. Ojo ${ }^{4}$, \\ Wesley C. Van Voorhis ${ }^{4}$, Luis-Miguel Ortega-Mora ${ }^{5}\left(\mathbb{D}\right.$ and Andrew Hemphill ${ }^{1, *(1)}$ \\ 1 Institute of Parasitology, Department of Infectious Diseases and Pathobiology, Vetsuisse Faculty, \\ University of Bern, Länggass-Strasse 122, 3012 Bern, Switzerland; pablo.winzer@vetsuisse.unibe.ch (P.W.); \\ dennis.imhof@vetsuisse.unibe.ch (D.I.); dominic.ritler@vetsuisse.unibe.ch (D.R.) \\ 2 Graduate School for Cellular and Biomedical Sciences, University of Bern, Mittelstrasse 43, \\ 3012 Bern, Switzerland \\ 3 Proteomics \& Mass Spectrometry Core Facility, Department for BioMedical Research (DBMR), \\ University of Berne, Freiburgstrasse 15, CH-3010 Berne, Switzerland; \\ anne-christine.uldry@dbmr.unibe.ch (A.-C.U.); sophie.lagache@dbmr.unibe.ch (S.B.-L.); \\ manfred.heller@dbmr.unibe.ch (M.H.) \\ 4 Center for Emerging and Re-emerging Infectious Diseases (CERID), Division of Allergy and Infectious \\ Diseases, Department of Medicine, University of Washington, Seattle, WA 98109, USA; \\ ojo67kk@yahoo.ca (K.K.O.); wesley@uw.edu (W.C.V.V.) \\ 5 SALUVET, Animal Health Department, Faculty of Veterinary Sciences, Complutense University of Madrid, \\ Ciudad Universitaria s/n, 28040 Madrid, Spain; luisucm@ucm.es \\ * Correspondence: joachim.mueller@vetsuisse.unibe.ch (J.M.); andrew.hemphill@vetsuisse.unibe.ch (A.H.); \\ Tel.: +41-31-631-23-84 (A.H.); Fax: +41-31-631-24-76 (A.H.) \\ + These authors contributed equally to this work.
}

Received: 4 May 2020; Accepted: 23 May 2020; Published: 26 May 2020

\begin{abstract}
Background: the apicomplexan parasite Neospora caninum causes important reproductive problems in farm animals, most notably in cattle. After infection via oocysts or tissue cysts, rapidly dividing tachyzoites infect various tissues and organs, and in immunocompetent hosts, they differentiate into slowly dividing bradyzoites, which form tissue cysts and constitute a resting stage persisting within infected tissues. Bumped kinase inhibitors (BKIs) of calcium dependent protein kinase 1 are promising drug candidates for the treatment of Neospora infections. BKI-1294 exposure of cell cultures infected with $N$. caninum tachyzoites results in the formation of massive multinucleated complexes (MNCs) containing numerous newly formed zoites, which remain viable for extended periods of time under drug pressure in vitro. MNC and tachyzoites exhibit considerable antigenic and structural differences. Methods: Using shotgun mass spectrometry, we compared the proteomes of tachyzoites to BKI-1294 induced MNCs, and analyzed the mRNA expression levels of selected genes in both stages. Results: More than half of the identified proteins are downregulated in MNCs as compared to tachyzoites. Only 12 proteins are upregulated, the majority of them containing SAG1 related sequence (SRS) domains, and some also known to be expressed in bradyzoites Conclusions: MNCs exhibit a proteome different from tachyzoites, share some bradyzoite-like features, but may constitute a third stage, which remains viable and ensures survival under adverse conditions such as drug pressure. We propose the term "baryzoites" for this stage (from Greek $\beta \alpha \rho v \sigma=$ massive, bulky, heavy, inert).
\end{abstract}

Keywords: antigenic variation; chemotherapy; drug adaptation; drug resistance 


\section{Introduction}

The phylum Apicomplexa parasites includes important pathogens for humans and animals. Among those, Neospora caninum, which is closely related to Toxoplasma gondii, causes abortion, stillbirth or birth of weak offspring in cattle, sheep and other ruminants, and also infects a wide range of other species [1]. Canines act as definitive hosts of N. caninum, and sexual development of the parasite in the intestinal tissue leads to the formation of oocysts, which are shed with the feces. Canines can also act as intermediate hosts and are affected by neurological symptoms [2]. Three stages are important for the life cycle of N. caninum, sporozoites, tachyzoites, and bradyzoites. Sporozoites develop within the oocysts and are orally infective. Tachyzoites represent the rapidly proliferating disease-causing stage, which infects numerous cell types and tissues, and can also cross the placenta and affect the developing fetus, which leads to malformations and/or abortion. The slowly proliferating bradyzoites are formed upon the immunological and physiological host response, and they represent a tissue cyst-forming stage that persists within infected tissues for extended periods. A temporal immunomodulation, such as during pregnancy, frequently leads to recrudescence and re-differentiation into tachyzoites which infect the developing fetus [3]. No vaccine is currently licensed for the prevention of bovine or canine neosporosis, and specific immuno- or chemotherapeutical treatments are lacking [4,5]. As a consequence, there is a keen interest in novel chemotherapeutics acting on specific targets [6].

Examples for such targets are calcium-dependent protein kinases (CDPKs). The genes coding for these kinases originate from plants [7], and therefore constitute interesting drug targets. During the last decade, CDPK1 has been an important focus as a target for drug development against a wide range of apicomplexans such as Plasmodium falciparum, Toxoplasma gondii, Neospora caninum, Sarcocystis neurona, Besnoitia besnoiti, Babesia bovis, Theileria equi and Cryptosporidium parvum [7,8]. Bumped kinase inhibitors (BKIs) are ATP-competitive kinase inhibitors that target CDPK1 in different apicomplexans [9]. They exhibit a high degree of efficacy and specificity for apicomplexan CDPK1 and are optimized to fit into a hydrophobic pocket within the ATP binding site. BKIs inhibit the ATP binding activity of a range of CDPK1 isoforms, including those of N. caninum [10]. They were shown to block invasion of invasive stages into host cells [10] and also inhibit microneme secretion, and thus invasion and egress [11]. Several BKIs have been studied so far with respect to efficacy against N. caninum infection, among them the pyrazolopyrimidine BKI-1294. This compound has shown highly promising efficacy in pregnant mouse models for neosporosis [12] and for toxoplasmosis [13], and in a pregnant sheep model for toxoplasmosis [14]. Moreover, other BKIs are effective against neosporosis, as shown in pregnant mouse [15] and sheep [16] models.

BKI-1294 does not act parasiticidal in vitro [17]. Prolonged exposure of mammalian cells infected with different Neospora isolates (Nc-1, Nc-Liv, and Nc-Spain7) and with the T. gondii strains RH and ME49 results in the formation of intracellular multinucleated complexes (MNCs) [12,17]. In addition, we found that BKI-1294-induced MNCs exhibited a deregulated gene expression pattern, as evidenced by the simultaneous expression of bradyzoite and tachyzoite antigens [12]. Immunofluorescence staining showed that the formation of MNCs during extended BKI-1294 treatment was accompanied by a lack of SAG1 surface expression and a decreased CDPK1 expression, and the formation of numerous zoites incapable of disjoining from each other. Following drug removal, proliferation continued, and zoites lacking NcSAG1 emerged from the periphery of these complexes, forming infective tachyzoites after 10 days [18]. These results suggested that MNCs could constitute a drug-induced resting stage that assures the survival of the parasite until the drug pressure is released.

To address this question, we have chosen proteomics as an appropriate tool. A number of studies had been carried out on the proteome of $N$. caninum previously. As one of the first methods, 2-D-Differential Gel electrophoresis (DIGE) was applied to define proteomic changes during tachyzoite-to-bradyzoite differentiation, identifying 20 proteins upregulated in tachyzoites and 6 in bradyzoites. However, this approach had technical limitations in that membrane proteins were not very well resolved [19]. Furthermore, proteomics was applied to identify potential virulence factors as exemplified by a study compared two isolates, namely Nc-Spain1H (low virulence) and Nc-Spain7 
(high virulence) during different steps of the lytic cycle [20]. To investigate BKI-1294-induced MNCs in more detail, we thus compared the proteomes of isolated tachyzoites to the proteomes of MNCs by shotgun mass spectrometry.

\section{Materials and Methods}

\subsection{Tissue Culture Media, Biochemicals, and Drugs}

If not stated otherwise, all tissue culture media were purchased from Gibco-BRL (Zürich, Switzerland), and biochemicals from Sigma (St. Louis, MO, USA). BKI-1294 was synthesized to $>99 \%$ purity by HPLC and NMR by Wuxi AppTech, Inc. (Wuhan, China) and provided by the Center for Emerging and Reemerging Infectious Diseases (CERID), Division of Allergy and Infectious Diseases, Department of Medicine, University of Washington (Seattle, WA, USA), and was stored in powder form, dry and protected from light at room temperature. For in vitro studies, $20 \mathrm{mM}$ stock solutions were prepared in dimethyl sulfoxide (DMSO) and they were stored at $-20{ }^{\circ} \mathrm{C}$. Primers for real-time PCR (RT-PCR) were purchased from Eurofins (Luxemburg, Luxemburg).

\subsection{Host Cell Cultivation and Parasite Maintenance}

Human foreskin fibroblasts (HFF; ATCC ${ }^{\circledR}$ SCRC-1041 ${ }^{\mathrm{TM}}$ ) were maintained in Dulbecco's modified Eagle medium (DMEM), containing phenol red, supplemented with $10 \%$ heat-inactivated and fetal calf serum (FCS), $100 \mathrm{U}$ of penicillin/mL, and $100 \mu \mathrm{g}$ streptomycin/mL. The Neospora caninum-Spain7 (Nc-Spain7) isolate was maintained by infecting semi-confluent HFF monolayers and cultivated at $37^{\circ} \mathrm{C}$ and $5 \% \mathrm{CO}_{2}$, with passages once or twice per week as previously described [21]. For induction of the formation of MNCs, N. caninum infected HFF were treated with $5 \mu \mathrm{M}$ BKI-1294 during 4-6 days.

\subsection{Microscopy}

Transmission electron microscopy (TEM) of BKI-1294-treated or non-treated Nc-Spain7-infected HFF was done as previously described [12,17]. In short, infected monolayers grown in T-25 tissue culture flasks were fixed in $2.5 \%$ glutaraldehyde in $100 \mathrm{mM}$ sodium cacodylate buffer $\mathrm{pH} 7.3$, removed from the flask by scraping, post-fixed in $2 \%$ osmium tetroxide in cacodylate buffer, and sequentially dehydrated in a graded (30-50-70-90-100\%) ethanol series. Specimens were embedded in Epon 812 epoxy resin, polymerized at $65^{\circ} \mathrm{C}$, and ultrathin sections were cut on a Reichert and Jung ultramicrotome (Reichert \& Jung, Vienna). Following transfer onto 300 mesh formvar-carbon coated nickel grids (Plano $\mathrm{GmbH}$, Marburg, Germany), they were stained in Uranyless ${ }^{\mathrm{TM}}$ and lead citrate (EMS, Hatfield, PA, USA), and specimens were inspected on a CM12 TEM operating at $80 \mathrm{kV}$.

For scanning electron microscopy (SEM), semi-confluent HFF monolayers were maintained in T175 cell culture flasks and were infected with Nc-Spain7 tachyzoites. At 4 h post infection, treatments with $5 \mu \mathrm{M}$ BKI-1294, or the corresponding amount of DMSO in controls were initiated, and cultures were maintained at $37^{\circ} \mathrm{C} / 5 \% \mathrm{CO}_{2}$ during 3 (controls) or 6 days (BKI-1294-treated cultures), until MNCs were formed. Subsequently, the infected monolayers were washed twice with PBS, followed by removal of infected cells with a rubber cell scraper and resuspension in PBS. After passaging the suspensions twice through a 25-gauge needle to break the host cells, MNCs and tachyzoites were separated from host cell debris by Sephadex G-25 chromatography. The parasite fractions in the flow through were collected by centrifugation ( $15 \mathrm{~min}, 1000 \times \mathrm{g}, 4^{\circ} \mathrm{C}$ ), washed twice with PBS, and were fixed in $2.5 \%$ glutaraldehyde and $2 \%$ osmium tetroxide, and dehydrated in ethanol as for TEM. They were finally washed twice in hexamethyl-disilazane (HDS), taken up in a small volume of HDS, and were allowed to settle onto glass coverslips under a fume hood. They were then sputter-coated with gold and inspected on a JEOL 840 SEM operating at $25 \mathrm{kV}$. 


\subsection{Proteomics}

Semi-confluent HFF monolayers were maintained in T175 cell culture flasks, and were infected with Nc-Spain7 tachyzoites. At 4 h post infection, treatment with $5 \mu \mathrm{M}$ BKI-1294, or the corresponding amount of DMSO in controls, was initiated, and cultures were maintained at $37{ }^{\circ} \mathrm{C} / 5 \% \mathrm{CO}_{2}$ during 3 (controls) or 6 days (BKI-1294-treated cultures), until multinucleated complexes (MNCs) were formed. Subsequently, the infected monolayers were washed twice with PBS, followed by removal of infected cells with a rubber cell scraper and resuspension in PBS. After passaging the suspensions twice through a 25 gauge needle to break the host cells, MNCs and tachyzoites were separated from host cell debris by Sephadex G-25 chromatography. The parasite fractions in the flow through were collected by centrifugation $\left(15 \mathrm{~min}, 1000 \times \mathrm{g}, 4^{\circ} \mathrm{C}\right)$ and washed twice with PBS, as described [21].

Cell pellets were lysed in $100 \mu \mathrm{L} 8 \mathrm{M}$ urea/100 mM Tris/ $\mathrm{HCl}$ pH 8/cOmplete ${ }^{\mathrm{TM}}$ protease inhibitor cocktail (Roche Diagnostics, Rotkreuz, Switzerland) by incubation for $15 \mathrm{~min}$ at RT followed by $15 \mathrm{~min}$ in an ultrasonic water bath. Proteins were reduced and alkylated with $10 \mathrm{mM}$ DTT for $30 \mathrm{~min}$ at $37^{\circ} \mathrm{C}$ and $50 \mathrm{mM}$ iodoacetamide for $30 \mathrm{~min}$ at $37^{\circ} \mathrm{C}$. Proteins were precipitated at $-20^{\circ} \mathrm{C}$ by addition of 5 volumes cold acetone and incubation at $-20^{\circ} \mathrm{C}$ overnight. All liquid was carefully removed, and the pellet dried in ambient air for $15 \mathrm{~min}$ before reconstitution of proteins in $200 \mu \mathrm{L}$ of $8 \mathrm{M}$ urea, $50 \mathrm{mM}$ Tris- $\mathrm{HCl} \mathrm{pH}$ 8.0. Protein concentration was determined by Bradford assay and an aliquot corresponding to $10 \mu \mathrm{g}$ protein was digested by trypsin (1:50 trypsin/protein ratio) for 6 hours at $37^{\circ} \mathrm{C}$ after dilution of urea concentration to $1.6 \mathrm{M}$ with $20 \mathrm{mM}$ Tris- $\mathrm{HCl} \mathrm{pH} 8.0$ and $2 \mathrm{mM} \mathrm{CaCl}_{2}$. The digests were acidified with TFA (1\%) and analyzed by LC-MS/MS. Three repetitive injections of an aliquot corresponding to $500 \mathrm{ng}$ of protein digest was separated on an EASY-nLC 1000 coupled to a QExactive mass spectrometer (ThermoFisher Scientific). Peptides were trapped on an Acclaim PepMap100 C18 pre-column ( $3 \mu \mathrm{m}, 100 \AA$, $75 \mu \mathrm{m} \times 2 \mathrm{~cm}$, ThermoFisher Scientific, Reinach, Switzerland) and separated by backflush on a C18 column $(3 \mu \mathrm{m}, 100 \AA, 75 \mu \mathrm{m} \times 15 \mathrm{~cm}$, Nikkyo Technos, Tokyo, Japan) by applying a $60 \mathrm{~min}$ gradient of $5 \%$ to $40 \%$ acetonitrile in water and $0.1 \%$ formic acid, at a flow rate of $400 \mathrm{~nL} / \mathrm{min}$. Peptides of m/z 360-1400 were detected with resolution of 70,000, applying an automatic gain control (AGC) target of $10^{6}$ and a maximum ion injection time of $50 \mathrm{~ms}$. A top ten data dependent method for precursor ion fragmentation with a stepped $27 \%$ normalized collision energy was applied with the following settings: precursor isolation width of $2 \mathrm{~m} / \mathrm{z}$, resolution 17,500, AGC of $10^{5}$ with a minimum target of $10^{3}$, maximum ion time of $110 \mathrm{~ms}$, charge exclusion of unassigned and $1+$ ions, peptide match on, and dynamic exclusion for 20 s, respectively.

\subsection{Measurement of RNA Expression Levels by Quantitative Reverse Transcriptase Real-Time PCR}

To determine the RNA levels of selected N. caninum genes (see Table 1), quantitative reverse transcriptase RT-PCR was performed as described [12,22]. Briefly, $8 \times 10^{4} \mathrm{HFF} /$ well were seeded onto 6 well plates and cultured for 4 days at $37^{\circ} \mathrm{C} / 5 \% \mathrm{CO}_{2}$ prior to infection with $6 \times 10^{5} \mathrm{~N}$. caninum tachyzoites/well. At $4 \mathrm{~h}$ post infection, the supernatant was aspirated and replaced with fresh medium containing either $5 \mu \mathrm{M}$ BKI-1294 to form MNCs, or the corresponding amount of DMSO to generate tachyzoites. At 3 days post infection in the case of tachyzoites or 6 days post infection in the case of MNCs, RNA was isolated using the Nucleospin ${ }^{\circledR}$ RNA Plus RNA isolation kit (Machery-Nagel, Düren, Germany) followed by cDNA synthesis using the Promega GoScript-Kit (Promega, Madison, WI, USA) according to the instructions provided by the manufacturers. Quantitative RT-PCR was performed using the Corbett Rotor gene 6000 (Qiagen, Venlo, Netherlands). The reactions contained $10 \mu \mathrm{L}$ Sybr-Green-Mix, $0.1 \mu \mathrm{L}$ of the forward and reverse primers listed in Table 1 and $10 \mu \mathrm{L}$ of cDNA. 
Table 1. List of primers used in this study.

\begin{tabular}{cccc}
\hline Annotation & Accession No & Primer & Sequence \\
\hline \multirow{2}{*}{ Nc28SrRNA } & \multirow{2}{*}{ L49389.1 } & Nc28S_F & TCTCTCTCACCAGGTTTAGG \\
& & Nc28S_R & CCGTGTTTCAAGACGGGTC \\
Bradyzoite antigen, putative (BAG1) & NCLIV_027470 & NcBAG1_F & CTCGACTTCATGGATGAGG \\
& & NcBAG1_R & CTTCTATGGTAACGTCATCC \\
Calcium dependent protein kinase 1 & NCLIV_011980 & NcCDPKI_F & AGACGCTGCTATCGCGGG \\
& & NcCDPKI_R & TTAGTTTCCGCAAAGCTTCAG \\
Inner membrane protein 1 & NCLIV_031770 & IMC1_F & GGATGGGACGGCGGTG \\
SRS-domain containing protein & NCLIV_019580 & Nc019580_F & CGCCACCGGCTGGATG \\
& & Nc019580_R & GTGCGTACCTCGGCGTGG \\
& & &
\end{tabular}

\subsection{Statistics}

The MS data were obtained from three biological replicates, with two technical replicates for each biological replicate. All MS data were processed by MaxQuant (version 1.5.4.1) with matching between runs for the same strain activated, but not between different strains, in order to avoid over-interpretation of the data. The sample sets were interpreted separately by MaxQuant. Fragment spectra were interpreted against a recent $N$. caninum protein sequence database in fasta format (ToxoDB-44_NcaninumLIV_AnnotatedProteins.fasta). The trypsin cleavage rule allowed amide bond cleavage after lysine and arginine but not if a proline follows, up to three missed cleavage sites, fixed carbamidomethylation modification of cysteines, variable oxidation of methionine and acetylation of protein $\mathrm{N}$-termini. Precursor and fragment mass tolerances were set to 10 and $20 \mathrm{ppm}$, respectively. Peptide spectrum matches and peptide and protein group identifications were filtered to a $1 \%$ false discovery rate (FDR) based on reversed database sequence matches, and a minimum of two razor or unique peptides were required to accept a protein group identification. Protein identifications considered as contaminations (e.g., trypsin or BSA) as well as proteins identified only by site (considered by MaxQuant developers as very likely false positives) were removed for statistical validation. The normalized label-free quantification (LFQ) protein group intensities as calculated by MaxQuant and the sum of the three most intense peptide intensities were used for relative proteome quantifications. First, we imputed missing protein LFQ values for samples in any condition group when there were at least two LFQ intensities in one group (downshift of 1.8 S.D. with a width of 0.3 S.D. [23]). Before summing, missing peptide intensities were imputed sample group wise, when there were at least 2 valid intensities (downshift of 1.8 S.D. with a width of 0.3 S.D.). The resulting protein intensities were named iTop3. This process left proteins without values in one or the other group. For Welch's T-tests, those missing protein intensities were replaced by imputed values from the very low end of intensity distributions in analogy to the above described imputation strategy (downshift 1.8 S.D., width of 0.3 S.D.). An FDR-controlled Benjamini-Hochberg procedure was used for correction of $p$-values. A log2-fold change of at least 1 and a corrected $p$-value of $\leq 0.05$ were required to be considered as significant. Statistical testing and imputation were made with a homemade $\mathrm{R}$ (version 3.6.2 script run under R-Studio).

\section{Results}

\subsection{Formation of MNCs upon BKI-1294 Treatment In Vitro}

Treatment of $N$. caninum infected HFF with $5 \mu \mathrm{M}$ BKI-1294 lead to the formation of intracellular MNCs within 3-6 days, which are comparatively visualized with non-drug-treated tachyzoites in Figure 1. TEM of non-treated tachyzoites showed intracellular parasites undergoing endodyogeny, situated within a parasitophorous vacuole (Figure 1A). Figure 1C shows an MNC that formed after 6 days of treatment with BKI-1294. These MNCs were also located within a parasitophorous vacuole, were structurally intact, viable, and exhibited the typical features of apicomplexan parasites, but were 
not able to disconnect from each other and thus remained intracellular. SEM was performed on MNCs and non-treated tachyzoites that were separated from host cell debris by Sephadex G25 chromatography (Figure 1B,D). MNCs exhibited multiple newly formed apical complexes that emerged out of the MNC surface, as indicated in Figure 1D.

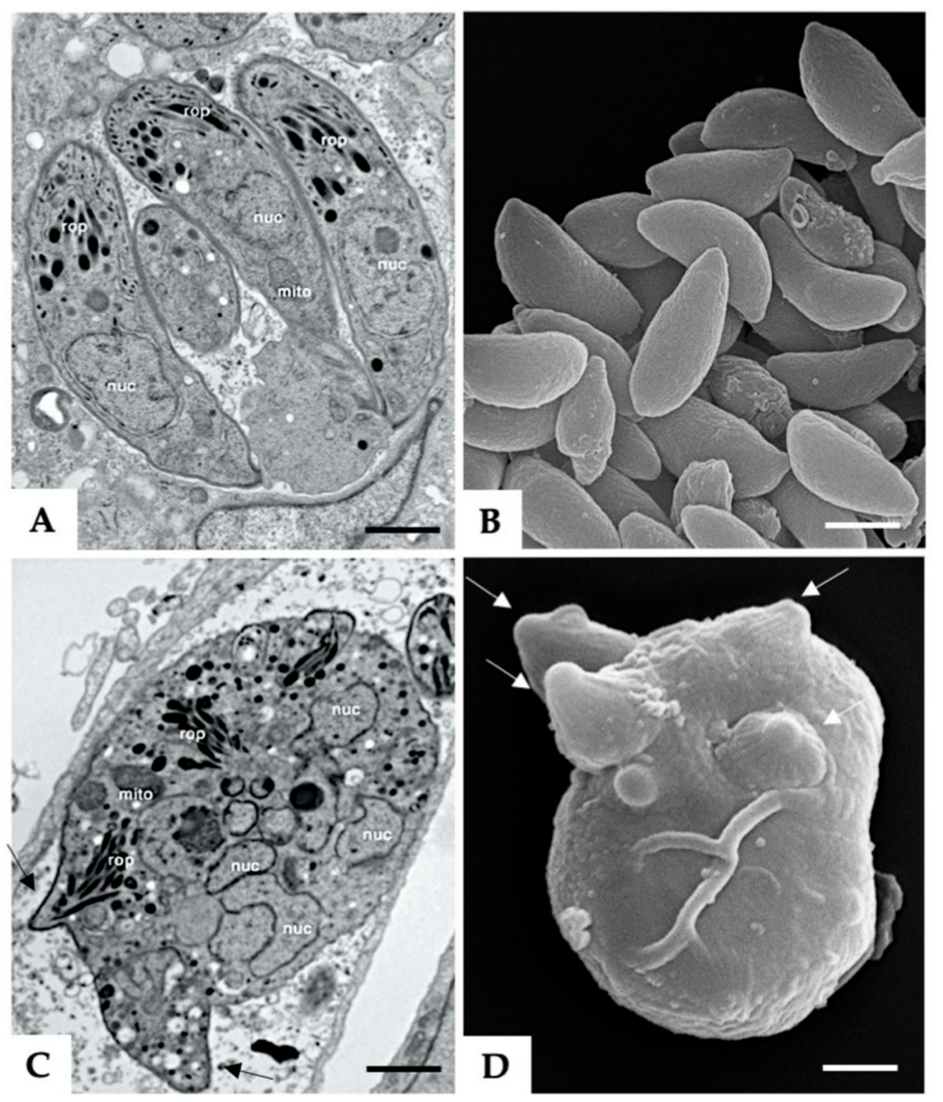

Figure 1. Tachyzoites (A,B) and BKI-1294 induced MNCs (C,D). (A,C) are TEM micrographs, with A showing individual tachyzoites situated within a parasitophorous vacuole, and (C) an MNC with multiple nuclei (nuc). Also visible are mitochondria (mito), rhoptries (rop), and apical complexes protruding from the MNC (black arrows). (B,D) are SEM micrographs of isolated tachyzoites and an MNC, respectively. Note the multiple apical complexes protruding from the surface of the MNC indicated by white arrows. Bar in $(\mathbf{A})=1 \mu \mathrm{m}$; bars in $(\mathbf{B}-\mathbf{D})=1.2 \mu \mathrm{m}$.

\subsection{The Proteome of Multinucleated Complexes Is Different from the Proteome of Tachyzoites}

Shotgun mass spectrometry of the proteomes of $N$. caninum tachyzoites and of BKI-induced MNCs resulted in the identification of 207,041 unique peptides matching to 2558 proteins (Table 2). The complete dataset is given in Table S1, which is available online.

Table 2. Summary of protein quantification data. N. caninum tachyzoites and MNCs were grown, purified and subjected to MS shotgun analysis as described in the Materials and Methods. For each group, three biological replicates have been tested (with 2 technical replicates per biological replicate). Only proteins with significant differences in both iTop3 and iLFQ levels were regarded as differential.

\begin{tabular}{cc}
\hline Parameter & Number \\
\hline Unique peptides & 207041 \\
Non-redundant proteins & 2558 \\
Higher in tachyzoites & 1325 \\
Higher in MNCs & 12 \\
Similar levels in both & 1221 \\
\hline
\end{tabular}


By deeper analysis, we identified 1337 proteins that were differential between both stages with respect to both iTop3 and iLFQ parameters, as explained in Section 2.6. The large majority had lower iLFQ and iTop3 levels in MNCs as compared to tachyzoites. Only 12 proteins had higher levels (Table 2).

Unbiased analysis of the dataset by principal component analysis (PCA) demonstrated for both iTop3 and iLFQ values (see Section 2.6) that the proteomes of tachyzoites and BKI-1294 induced MNCs formed non-overlapping clusters separated by principal component 1 (PC1). Moreover, the proteomes of biological and technical replicates clustered together for MNCs whereas the proteomes of biological and technical replicates of tachyzoites were separated along PC2 (Figure 2).

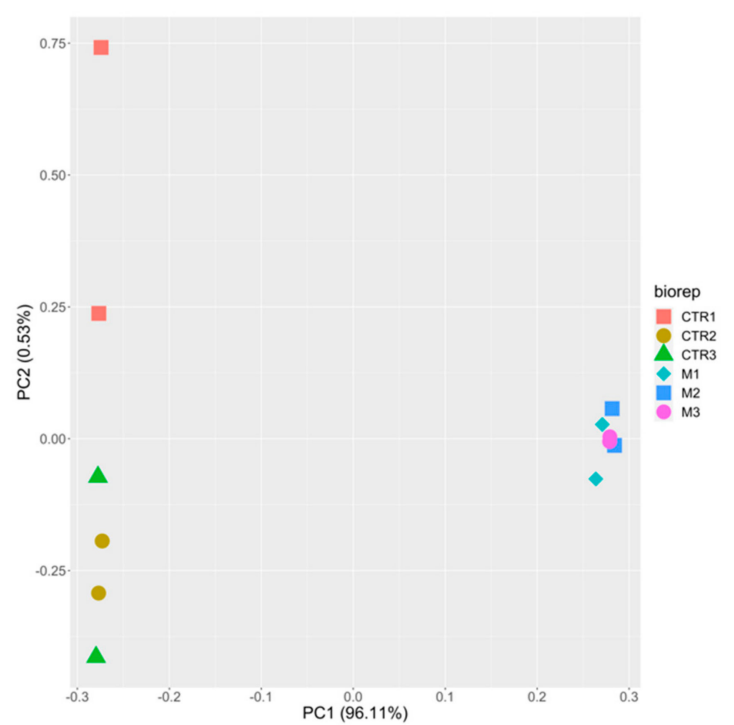

A

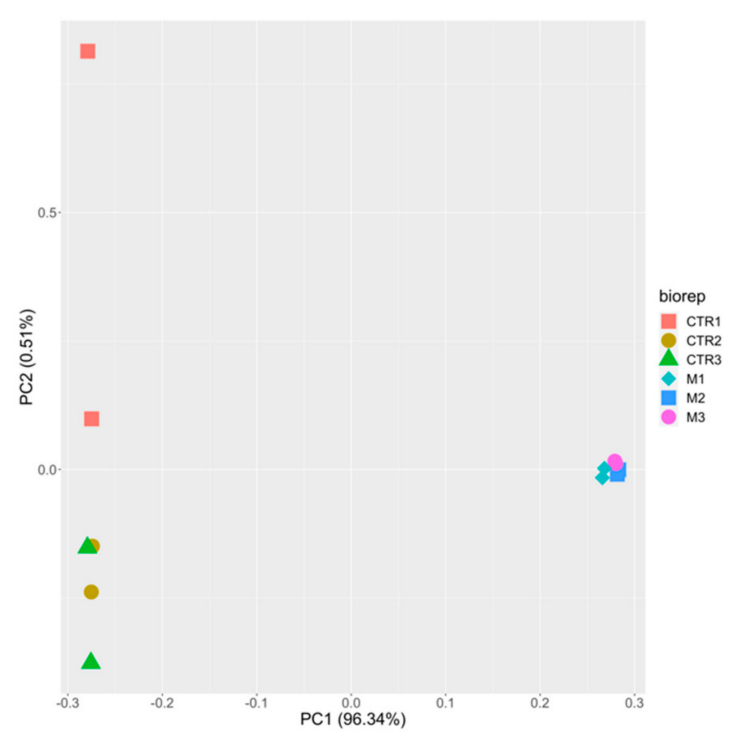

B

Figure 2. Principal component analysis of proteome data sets from $N$. caninum tachyzoites and from MNCs induced by BKI-1294 treatment. Tachyzoites and MNCs were grown, purified and subjected to MS shotgun analysis as described in the Materials and Methods. All technical and biological replicates are shown, namely red square, brown circle, and green triangle for tachyzoites (CTR), and pink circle, blue square, and turquoise diamond for MNCs (M). (A) iTop3 data; (B) iLFQ data.

\subsection{Multinucleated Complexes Express a Distinct Set of Potential Surface Antigens}

A closer look at the 12 proteins with higher levels in MNCs compared to tachyzoites revealed that seven proteins had N-terminally located signal peptides, and six proteins had one or more SRS-domains (Table 3).

Table 3. List of proteins overexpressed in MNCs formed by BKI-1294 treatment of Neospora caninum infected HFF monolayers. The NCLIV_ accession numbers in the ToxoDB database are given. IF, translation initiation factor; SP, signal peptide; SRS, SAG1-related surface antigen; TM, transmembrane.

\begin{tabular}{ccc}
\hline Accession No & Annotation & Protein Features and Properties \\
\hline 001830 & Hypothetical protein & SP; homologies to IF2 and collagen. \\
010030 & Sradyzoite surface protein BSR4 & SRS domains \\
010050 & SRS domain-containing protein & MGC83258 protein, related \\
019520 & SRS domain-containing protein & $\begin{array}{c}\text { 1.7 MDa protein; homologies to ubiquitin ligase and mucin } \\
\text { SP, SRS domain, 2 TM domains, 1 lipoprotein domain, } \\
\text { homology to T. gondii, bradyzoite surface antigen. }\end{array}$ \\
019580 & Annotated as SAG4. \\
022800 & Conserved hypothetical protein & Homologies to serine-rich adhesion and collagen \\
035375 & SRS domain-containing protein & SRS domains \\
\hline
\end{tabular}


Table 3. Cont.

\begin{tabular}{ccc}
\hline Accession No & Annotation & Protein Features and Properties \\
\hline 044320 & Zinc finger protein 467, related & Homologies to serine-rich adhesins \\
044430 & Hypothetical protein & Short sequences with homologies to zinc finger proteins and \\
061850 & SRS domain-containing protein & ATP-ase domain of Hsp90 \\
069001 & SRS domain-containing protein & SP, 2 SRS domains. \\
069110 & Hypothetical protein & SP \\
\hline
\end{tabular}

The relative abundance of these 12 proteins given by their respective iLFQ intensities-negligible in tachyzoites-reached up to $10^{8}$ iLFQ units in MNCs in the case of the SRS-domain containing protein NCLIV_019580, formerly annotated as SAG4 (Figure 3).

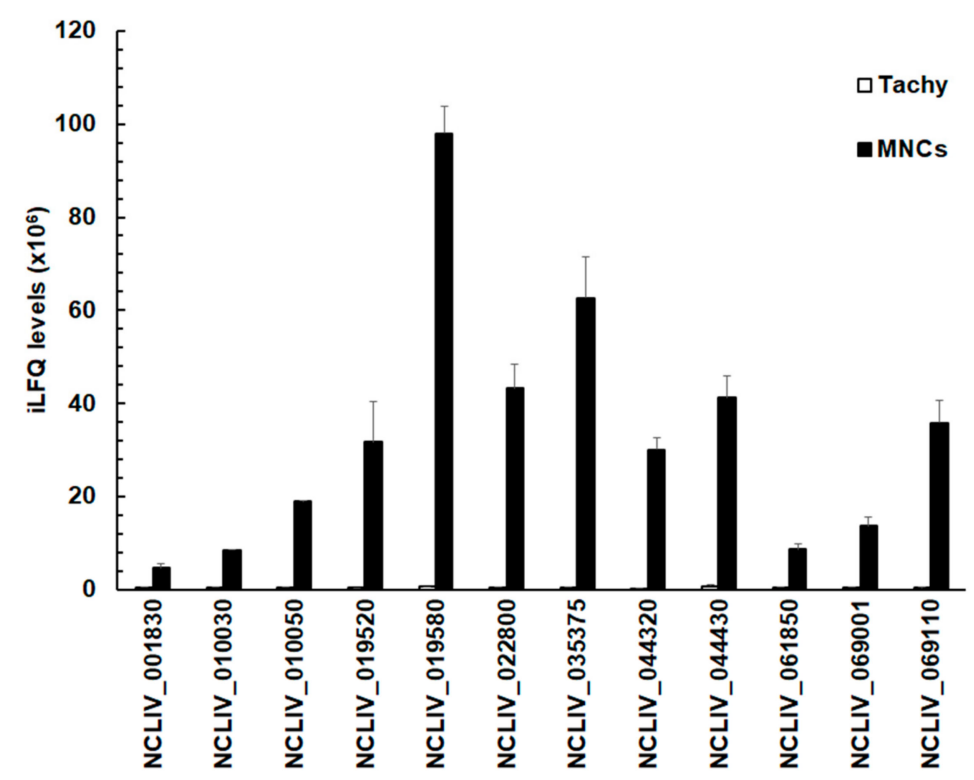

Figure 3. Quantitative assessments of the proteins in tachyzoites (Tachy, white bars) and MNCs (MNCs, black bars) listed in Table 3. For all proteins, mean values \pm one standard deviation for LFQ intensities $\left(\times 10^{6}\right)$ in three biological replicates are shown. The proteins are termed by their respective accession numbers in the ToxoDB.

These values were, however, more than two orders of magnitude lower than the amount of the major surface antigen 1 of $N$. caninum, Nc SAG1 (NCLIV_033230). NcSAG1 reached $20.3 \pm 1.3 \times 10^{9}$ iLFQ units in tachyzoites and $19.9 \pm 0.7 \times 10^{9}$ iLFQ units in MNCs (Table S1).

3.4. The SRS Domain Containing Protein NCLIV_019580 (NcSAG4) Has Higher mRNA Expression Levels in MNCs Compared to Tachyzoites

Since the SRS-domain containing protein encoded by NCLIV_019580, also annotated as NcSAG4, had the highest differential protein level in MNCs (see Figure 2), we investigated whether the NcSAG4 protein levels were correlated to the respective mRNA expression levels. We compared the mRNA levels in tachyzoites and MNCs of the corresponding coding sequence to N. caninum 28S RNA and included three other transcripts, namely mRNA coding for BAG1, IMC1, and CDPK1, the target of BKI-1294, into this comparison. As shown in Figure 4, MNCs had higher NcSAG4 mRNA levels compared to tachyzoites. 


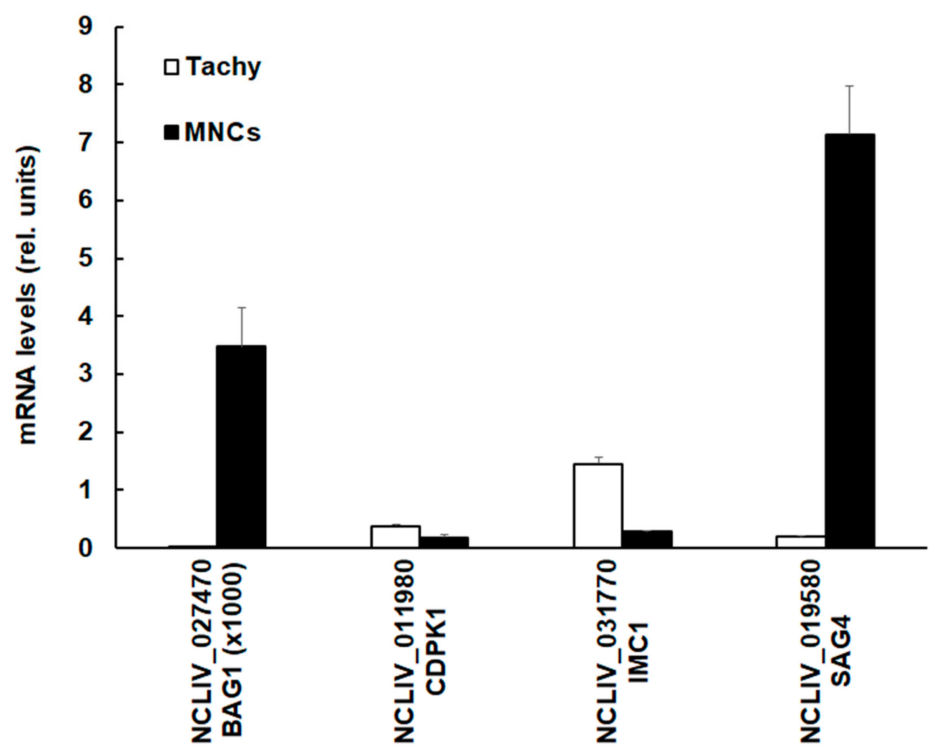

Figure 4. Quantitative assessments of mRNA levels of four selected genes. Confluent human foreskin fibroblast monolayers were infected with $N$. caninum tachyzoites and left untreated for the generation of tachyzoites (Tachy, white bars) or treated with BKI-1294 in order to generate MNCs (MNCs; black bars). Cells were harvested, mRNA was extracted, cDNA was prepared, and mRNA levels were quantified as described in Section 2.5. Mean \pm standard error values from four replicates were assessed and expression levels were given as values in arbitrary units relative to the amount of $28 \mathrm{~S}$ rRNA. The genes are termed by their respective accession numbers in ToxoDB.

The same was found for the expression level of mRNA coding for NcBAG1. The absolute mRNA levels of BAG1 were, however, three magnitudes lower than those of the three other genes investigated. Conversely, the levels of mRNAs encoding CDPK1 and IMC1 were lower in MNCs than in tachyzoites.

\section{Discussion}

The proteome dataset generated for this study, comparing protein expression in BKI-1294-induced MNC and tachyzoites, contained 2558 non-redundant proteins, corresponding to $36 \%$ of the 7121 open reading frames identified in the N. caninum genome [24], thus nearly two times more than the number of proteins identified in a previous study [20].

In our comparative analysis of MNCs and tachyzoites, more than half of these proteins, including key enzymes of energy and intermediary metabolism (see Table S1 for details), are downregulated in MNCs induced by BKI-1294 treatment, and only twelve proteins are upregulated in MNCs. This suggests that MNCs may represent a resting state of the parasite that is induced by drug pressure exerted through BKI-1294 treatment.

This hypothesis is backed by the finding that mRNA coding for NcBAG1 (NCLIV_027470), also known as a heat-shock protein and a well-established marker for bradyzoites [25], can be detected in MNCs, but not in tachyzoites. The same has not only been observed in MNCs induced by BKI-1294 in a previous study [12], but also in intracellular parasites exposed to a different class of compounds, namely artemisinin derivatives such as artemisone and GC012 [22]. In addition, these findings were confirmed on the protein level by observing increased anti-BAG1 antibody staining in HFF infected with N. caninum and treated with these compounds [22]. The corresponding NcBAG1 protein is, however, not included in the proteome dataset (see Table S1), suggesting that its expression levels are below the resolution limit of the method. Conversely, two other bradyzoite antigens, namely the SRS domain containing proteins NCLIV_010030, the bradyzoite antigen NcBSR4 [26], and NCLIV_019580, formerly annotated as NcSAG4, are amongst the twelve MNC-upregulated proteins. Of these, NcSAG4 exhibits the highest expression levels. 
The N. caninum SRS domain containing protein superfamily comprises 227 genes and 52 pseudogenes [24], considerably more than Toxoplasma gondii strains [27]. The most prominent of these proteins is certainly SAG1 (NCLIV_033230), the major surface antigen of N. caninum. During the last two decades, NcSAG1 has been investigated as a candidate for recombinant vaccine development [28,29] and for immunodiagnosis [30-32]. SAG1, considered an antigen expressed only in tachyzoites [33], is expressed at equally high levels in tachyzoites and MNCs, and therefore would not account for an immunological differentiation of both stages. Conversely, in our experiment, the bradyzoite-specific NcSAG4 [34] is expressed in MNCs only, most likely by regulation on the transcriptional level. Similarly, SAG4 expression has been shown to be upregulated in intracellular parasites treated with artemisinin derivatives such as artemisone and GC007 [22]. However, these derivatives have a different mode of action, and treatments of parasites induced completely different alterations. Nevertheless, also artemisone and GC007 required in vitro treatments at a concentration of $5 \mu \mathrm{M}$ over a period of over 20 days in order to act parasiticidal, similar to what has been observed for BKI-1294 [12]. Thus, upregulation of NcSAG4 expression could be a general reaction to adverse physiological conditions, similar to what has been postulated for bradyzoites and tissue cyst formation [35].

Besides SAG4, six other MNC-induced proteins contain signal peptides and thus may constitute surface antigens, or secretory proteins involved in modulating the parasite-host interface. Five other proteins have SRS-domains. These overexpressed proteins may constitute suitable candidates for immunological investigations in vivo and-if this hypothesis could be confirmed-for recombinant vaccine development.

Constitutive expression of NcSAG4 in N. caninum tachyzoites had been shown to confer protection against vertical transmission in a mouse model [36]. Therefore, it is conceivable that the excellent protective effects of BKI-1294 and related compounds against vertical transmission [12,14-16] may be due to the induction of MNCs that express a set of diverse surface antigens, including NcSAG4. However, we currently do not know whether these antigens are expressed on the surface of newly formed zoites, or on the MNC surface. In any case, members of the SRS protein family are usually anchored to the plasma membrane by a glycosylphosphatidylinositol (GPI) molecule [37,38]. Besides NcSAG1 and NcSRS2 (also known as SRS29B and NcSRS29C, respectively), other SRS family members have been studied, including NcSRS67 that has no orthologue in T. gondii [39], and NcSRS57, which is expressed in both tachyzoites and bradyzoites $[40,41]$. However, according to our proteomics study, none of these appear to be overexpressed in MNCs.

Two additional studies described the development of similar multinucleated forms of the closely related T. gondii. Sugi et al. reported on another BKI named 1NM-PP1, which targeted T. gondii mitogen-activated protein kinase-like 1 (TgMAPKL-1), interfered in the cell cycle, and induced the formation enlarged multinucleated parasites. A mutation in a gatekeeper amino acid of TgMAPKL-1 led to a significant reduction in drug sensitivity and a reduction of enlarged multinucleated parasite formation [42]. In another study, a targeted deletion of the rab11a gene in T. gondii (TGME49_289680) also induced similar phenotypic changes [43]. The closest homologue in N. caninum, the unspecified protein NCLIV_041930, is expressed at similar levels in both tachyzoites and BKI-1294 induced MNCs (see Table S1).

Overall, we may consider that drug treatment, in the present case BKI-1294, does not only cause a shutdown of housekeeping gene expression and morphological alterations, but may also initiate "antigenic variation", albeit to a much lesser extent than in other protozoan parasites such as the apicomplexan Plasmodium sp. [44], the Excavata Trypanosoma sp. [45,46] and Giardia lamblia [47]. MNC formation may thus constitute a response strategy to ensure the survival in the presence of BKIs and perhaps other compounds. Here, further investigations are required, also with respect to the infective potential of these MNCs. It is noteworthy to mention that similar multinucleated stages were induced upon in vitro treatment of T. gondii with diclazuril [48]. Diclazuril is triazinone derivative that is effective against intracellular stages of Eimeria and Isospora spp. While the mechanism of this drug is not well understood, it was shown that diclazuril is targeting enzymes of the respiratory 
chain and other enzymes such as dihydrofolate reductase (DHFR) [49]. However, we propose that MNCs represent a stage designated as baryzoites (Greek $\beta \alpha \varrho v \sigma=$ massive, bulky, heavy, inert) as they represent a heavily enlarged parasitic stage that ensures survival of these parasites at increased drug concentrations during prolonged periods of time.

Supplementary Materials: The following are available online at http://www.mdpi.com/2076-2607/8/6/801/s1, Table S1. Proteome data set of N. caninum tachyzoites and of MNCs induced by BKI-1294 treatment of infected cells. Parasites were grown and subjected to MS shotgun analysis as described in the Materials and Methods.

Author Contributions: Conceptualization, A.H., P.W., J.M., K.K.O.; W.C.V.V.; methodology, P.W., D.I., J.M., A.H., A.-C.U., S.B.-L., M.H.; investigation, P.W., D.I., J.M., A.H.; resources, A.H., K.K.O., W.C.V.V., L.-M.O.-M.; data curation, J.M., A.H., P.W., A.-C.U., M.H., D.R.; writing—original draft preparation, J.M., P.W., A.H.; writing-review and editing, J.M., A.H., M.H., D.R., K.K.O., W.C.V.V., L.-M.O.-M.; visualization, A.H., A.-C.U.; P.W., D.I.; supervision, A.H.; project administration, A.H.; funding acquisition, A.H., K.K.O., W.C.V.V., L.-M.O.-M. All authors have read and agreed to the published version of the manuscript.

Funding: This research was funded by the Swiss National Science Foundation, grant number 310030_184662, and the National Institutes of Health (NIH) grants R01AI089441, R01AI111341, R21AI123690, and R21AI140881.

Acknowledgments: Many thanks are addressed to Vreni Balmer and Nicoleta Anghel for help in cell culture and sample preparation, to Dustin Maly and his laboratory for originally synthesizing BKI-1294 and related BKI compounds, and to Rama Subba Rao Vidadala, Lynn K. Barrett, Ryan Choi, Grant Whitman, Samantha A. Michaels and Mathew A. Hulverson for quality control and shipping of BKI-1294.

Conflicts of Interest: W.C.V.V. is an owner/officer of ParaTheraTech Inc., a company which is seeking to bring bumped kinase inhibitors to the animal health market.

\section{References}

1. Goodswen, S.J.; Kennedy, P.J.; Ellis, J.T. A review of the infection, genetics, and evolution of Neospora caninum: From the past to the present. Infect. Genet. Evol. 2013, 13, 133-150. [CrossRef] [PubMed]

2. Coelho, A.M.; Cherubini, G.; De Stefani, A.; Negrin, A.; Gutierrez-Quintana, R.; Bersan, E.; Guevar, J. Serological prevalence of toxoplasmosis and neosporosis in dogs diagnosed with suspected meningoencephalitis in the UK. J. Small Anim. Pract. 2019, 60, 44-50. [CrossRef] [PubMed]

3. Dubey, J.P.; Hemphill, A.; Calero-Bernal, R.; Schares, G. Neosporosis in Animals; Taylor \& Francis: Boca Raton, FL, USA, 2017.

4. Hemphill, A.; Aguado-Martinez, A.; Müller, J. Approaches for the vaccination and treatment of Neospora caninum infections in mice and ruminant models. Parasitology 2016, 143, 245-259. [CrossRef] [PubMed]

5. Reichel, M.P.; McAllister, M.M.; Pomroy, W.E.; Campero, C.; Ortega-Mora, L.M.; Ellis, J.T. Control options for Neospora caninum-is there anything new or are we going backwards? Parasitology 2014, 141, 1455-1470. [CrossRef] [PubMed]

6. Müller, J.; Hemphill, A. New approaches for the identification of drug targets in protozoan parasites. Int. Rev. Cell Mol. Biol. 2013, 301, 359-401. [CrossRef]

7. Van Voorhis, W.C.; Doggett, J.S.; Parsons, M.; Hulverson, M.A.; Choi, R.; Arnold, S.L.M.; Riggs, M.W.; Hemphill, A.; Howe, D.K.; Mealey, R.H.; et al. Extended-spectrum antiprotozoal bumped kinase inhibitors: A review. Exp. Parasitol. 2017, 180, 71-83. [CrossRef]

8. Choi, R.; Hulverson, M.A.; Huang, W.; Vidadala, R.S.R.; Whitman, G.R.; Barrett, L.K.; Schaefer, D.A.; Betzer, D.P.; Riggs, M.W.; Doggett, J.S.; et al. Bumped Kinase Inhibitors as therapy for apicomplexan parasitic diseases: Lessons learned. Int. J. Parasitol. 2020. [CrossRef]

9. Ojo, K.K.; Larson, E.T.; Keyloun, K.R.; Castaneda, L.J.; Derocher, A.E.; Inampudi, K.K.; Kim, J.E.; Arakaki, T.L.; Murphy, R.C.; Zhang, L.; et al. Toxoplasma gondii calcium-dependent protein kinase 1 is a target for selective kinase inhibitors. Nat. Struct. Mol. Biol. 2010, 17, 602-607. [CrossRef]

10. Johnson, S.M.; Murphy, R.C.; Geiger, J.A.; DeRocher, A.E.; Zhang, Z.; Ojo, K.K.; Larson, E.T.; Perera, B.G.; Dale, E.J;; He, P.; et al. Development of Toxoplasma gondii calcium-dependent protein kinase 1 (TgCDPK1) inhibitors with potent anti-toxoplasma activity. J. Med. Chem. 2012, 55, 2416-2426. [CrossRef]

11. Lourido, S.; Tang, K.; Sibley, L.D. Distinct signalling pathways control Toxoplasma egress and host-cell invasion. $E M B O$ J. 2012, 31, 4524-4534. [CrossRef] 
12. Winzer, P.; Müller, J.; Aguado-Martinez, A.; Rahman, M.; Balmer, V.; Manser, V.; Ortega-Mora, L.M.; Ojo, K.K.; Fan, E.; Maly, D.J.; et al. In vitro and In vivo Effects of the bumped kinase inhibitor 1294 in the related cyst-forming apicomplexans Toxoplasma gondii and Neospora caninum. Antimicrob. Agents Chemother. 2015, 59, 6361-6374. [CrossRef] [PubMed]

13. Müller, J.; Aguado-Martinez, A.; Ortega-Mora, L.M.; Moreno-Gonzalo, J.; Ferre, I.; Hulverson, M.A.; Choi, R.; McCloskey, M.C.; Barrett, L.K.; Maly, D.J.; et al. Development of a murine vertical transmission model for Toxoplasma gondii oocyst infection and studies on the efficacy of bumped kinase inhibitor (BKI)-1294 and the naphthoquinone buparvaquone against congenital toxoplasmosis. J. Antimicrob. Chemother. 2017, 72, 2334-2341. [CrossRef] [PubMed]

14. Sanchez-Sanchez, R.; Ferre, I.; Re, M.; Ramos, J.J.; Regidor-Cerrillo, J.; Pizarro Diaz, M.; Gonzalez-Huecas, M.; Tabanera, E.; Benavides, J.; Hemphill, A.; et al. Treatment with bumped kinase inhibitor 1294 is safe and leads to significant protection against abortion and vertical transmission in sheep experimentally Iifected with Toxoplasma gondii during pregnancy. Antimicrob. Agents Chemother. 2019, 63. [CrossRef] [PubMed]

15. Müller, J.; Aguado-Martinez, A.; Balmer, V.; Maly, D.J.; Fan, E.; Ortega-Mora, L.M.; Ojo, K.K.; Van Voorhis, W.C.; Hemphill, A. Two novel calcium-dependent protein kinase 1 Inhibitors interfere with vertical transmission in mice infected with Neospora caninum tachyzoites. Antimicrob. Agents Chemother. 2017, 61. [CrossRef] [PubMed]

16. Sanchez-Sanchez, R.; Ferre, I.; Re, M.; Vazquez, P.; Ferrer, L.M.; Blanco-Murcia, J.; Regidor-Cerrillo, J.; Pizarro Diaz, M.; Gonzalez-Huecas, M.; Tabanera, E.; et al. Safety and efficacy of the bumped kinase inhibitor BKI-1553 in pregnant sheep experimentally infected with Neospora caninum tachyzoites. Int. J. Parasitol. Drugs Drug Resist. 2018, 8, 112-124. [CrossRef]

17. Ojo, K.K.; Reid, M.C.; Kallur Siddaramaiah, L.; Müller, J.; Winzer, P.; Zhang, Z.; Keyloun, K.R.; Vidadala, R.S.; Merritt, E.A.; Hol, W.G.; et al. Neospora caninum calcium-dependent protein kinase 1 is an effective drug target for neosporosis therapy. PLoS ONE 2014, 9, e92929. [CrossRef]

18. Winzer, P.; Anghel, N.; Imhof, D.; Balmer, V.; Ortega-Mora, L.M.; Ojo, K.K.; Van Voorhis, W.C.; Müller, J.; Hemphill, A. Neospora caninum: Structure and fate of multinucleated complexes induced by the bumped kinase inhibitor BKI-1294. Pathogens 2020, 9, 382. [CrossRef]

19. Marugan-Hernandez, V.; Alvarez-Garcia, G.; Risco-Castillo, V.; Regidor-Cerrillo, J.; Ortega-Mora, L.M. Identification of Neospora caninum proteins regulated during the differentiation process from tachyzoite to bradyzoite stage by DIGE. Proteomics 2010, 10, 1740-1750. [CrossRef]

20. Horcajo, P.; Xia, D.; Randle, N.; Collantes-Fernandez, E.; Wastling, J.; Ortega-Mora, L.M.; Regidor-Cerrillo, J. Integrative transcriptome and proteome analyses define marked differences between Neospora caninum isolates throughout the tachyzoite lytic cycle. J. Proteom. 2018, 180, 108-119. [CrossRef]

21. Hemphill, A.; Gottstein, B.; Kaufmann, H. Adhesion and invasion of bovine endothelial cells by Neospora caninum. Parasitology 1996, 112 (Pt 2), 183-197. [CrossRef]

22. Müller, J.; Balmer, V.; Winzer, P.; Rahman, M.; Manser, V.; Haynes, R.K.; Hemphill, A. In vitro effects of new artemisinin derivatives in Neospora caninum-infected human fibroblasts. Int. J. Antimicrob. Agents 2015, 46, 88-93. [CrossRef] [PubMed]

23. Nash, T.E.; Luján, H.T.; Mowatt, M.R.; Conrad, J.T. Variant-specific surface protein switching in Giardia lamblia. Infect. Immun. 2001, 69, 1922-1923. [CrossRef] [PubMed]

24. Reid, A.J.; Vermont, S.J.; Cotton, J.A.; Harris, D.; Hill-Cawthorne, G.A.; Konen-Waisman, S.; Latham, S.M.; Mourier, T.; Norton, R.; Quail, M.A.; et al. Comparative genomics of the apicomplexan parasites Toxoplasma gondii and Neospora caninum: Coccidia differing in host range and transmission strategy. PLoS Pathog. 2012, 8, e1002567. [CrossRef] [PubMed]

25. Kobayashi, T.; Narabu, S.; Yanai, Y.; Hatano, Y.; Ito, A.; Imai, S.; Ike, K. Gene cloning and characterization of the protein encoded by the Neospora caninum bradyzoite-specific antigen gene BAG1. J. Parasitol. 2013, 99, 453-458. [CrossRef]

26. Risco-Castillo, V.; Fernandez-Garcia, A.; Zaballos, A.; Aguado-Martinez, A.; Hemphill, A.; Rodriguez-Bertos, A.; Alvarez-Garcia, G.; Ortega-Mora, L.M. Molecular characterisation of BSR4, a novel bradyzoite-specific gene from Neospora caninum. Int. J. Parasitol. 2007, 37, 887-896. [CrossRef]

27. Wasmuth, J.D.; Pszenny, V.; Haile, S.; Jansen, E.M.; Gast, A.T.; Sher, A.; Boyle, J.P.; Boulanger, M.J.; Parkinson, J.; Grigg, M.E. Integrated bioinformatic and targeted deletion analyses of the SRS gene superfamily identify SRS29C as a negative regulator of Toxoplasma virulence. mBio 2012, 3. [CrossRef] 
28. Bengoa-Luoni, S.A.; Corigliano, M.G.; Sanchez-Lopez, E.; Albarracin, R.M.; Legarralde, A.; Ganuza, A.; Clemente, M.; Sander, V.A. The potential of a DIVA-like recombinant vaccine composed by rNcSAG1 and rAtHsp81.2 against vertical transmission in a mouse model of congenital neosporosis. Acta Trop. 2019, 198, 105094. [CrossRef]

29. Cannas, A.; Naguleswaran, A.; Muller, N.; Eperon, S.; Gottstein, B.; Hemphill, A. Vaccination of mice against experimental Neospora caninum infection using NcSAG1- and NcSRS2-based recombinant antigens and DNA vaccines. Parasitology 2003, 126, 303-312. [CrossRef]

30. Liao, M.; Zhang, S.; Xuan, X.; Zhang, G.; Huang, X.; Igarashi, I.; Fujisaki, K. Development of rapid immunochromatographic test with recombinant NcSAG1 for detection of antibodies to Neospora caninum in cattle. Clin. Diagn. Lab. Immunol. 2005, 12, 885-887. [CrossRef]

31. Moraveji, M.; Hosseini, A.; Moghaddar, N.; Namavari, M.M.; Eskandari, M.H. Development of latex agglutination test with recombinant NcSAG1 for the rapid detection of antibodies to Neospora caninum in cattle. Vet. Parasitol. 2012, 189, 211-217. [CrossRef]

32. Zhou, M.; Cao, S.; Sevinc, F.; Sevinc, M.; Ceylan, O.; Liu, M.; Wang, G.; Moumouni, P.F.; Jirapattharasate, C.; Suzuki, H.; et al. Enzyme-linked immunosorbent assays using recombinant TgSAG2 and NcSAG1 to detect Toxoplasma gondii and Neospora caninum-specific antibodies in domestic animals in Turkey. J. Vet. Med Sci. Jpn. Soc. Vet. Sci. 2017, 78, 1877-1881. [CrossRef] [PubMed]

33. Vonlaufen, N.; Müller, N.; Keller, N.; Naguleswaran, A.; Bohne, W.; McAllister, M.M.; Bjorkman, C.; Muller, E.; Caldelari, R.; Hemphill, A. Exogenous nitric oxide triggers Neospora caninum tachyzoite-to-bradyzoite stage conversion in murine epidermal keratinocyte cell cultures. Int. J. Parasitol. 2002, 32, 1253-1265. [CrossRef]

34. Aguado-Martinez, A.; Ortega-Mora, L.M.; Alvarez-Garcia, G.; Rodriguez-Marco, S.; Risco-Castillo, V.; Marugan-Hernandez, V.; Fernandez-Garcia, A. Stage-specific expression of Nc SAG4 as a marker of chronic Neospora caninum infection in a mouse model. Parasitology 2009, 136, 757-764. [CrossRef] [PubMed]

35. Fernandez-Garcia, A.; Risco-Castillo, V.; Zaballos, A.; Alvarez-Garcia, G.; Ortega-Mora, L.M. Identification and molecular cloning of the Neospora caninum SAG4 gene specifically expressed at bradyzoite stage. Mol. Biochem. Parasitol. 2006, 146, 89-97. [CrossRef] [PubMed]

36. Marugan-Hernandez, V.; Ortega-Mora, L.M.; Aguado-Martinez, A.; Jimenez-Ruiz, E.; Alvarez-Garcia, G. Transgenic Neospora caninum strains constitutively expressing the bradyzoite NcSAG4 protein proved to be safe and conferred significant levels of protection against vertical transmission when used as live vaccines in mice. Vaccine 2011, 29, 7867-7874. [CrossRef]

37. Fuchs, N.; Sonda, S.; Gottstein, B.; Hemphill, A. Differential expression of cell surface- and dense granule-associated Neospora caninum proteins in tachyzoites and bradyzoites. J. Parasitol. 1998, 84, 753-758. [CrossRef]

38. Schares, G.; Zinecker, C.F.; Schmidt, J.; Azzouz, N.; Conraths, F.J.; Gerold, P.; Schwarz, R.T. Structural analysis of free and protein-bound glycosyl-phosphatidylinositols of Neospora caninum. Mol. Biochem. Parasitol. 2000, 105, 155-161. [CrossRef]

39. Bezerra, M.A.; Pereira, L.M.; Bononi, A.; Biella, C.A.; Baroni, L.; Pollo-Oliveira, L.; Yatsuda, A.P. Constitutive expression and characterization of a surface SRS (NcSRS67) protein of Neospora caninum with no orthologue in Toxoplasma gondii. Parasitol. Int. 2017, 66, 173-180. [CrossRef]

40. Bezerra, M.A.; Pereira, L.M.; Baroni, L.; Yatsuda, A.P. The soluble fraction of Neospora caninum treated with PI-PLC is dominated by NcSRS29B and NcSRS29C. Exp. Parasitol. 2019, 204, 107731. [CrossRef]

41. Pollo-Oliveira, L.; Post, H.; Acencio, M.L.; Lemke, N.; van den Toorn, H.; Tragante, V.; Heck, A.J.; Altelaar, A.F.; Yatsuda, A.P. Unravelling the Neospora caninum secretome through the secreted fraction (ESA) and quantification of the discharged tachyzoite using high-resolution mass spectrometry-based proteomics. Parasites Vectors 2013, 6, 335. [CrossRef]

42. Sugi, T.; Ma, Y.F.; Tomita, T.; Murakoshi, F.; Eaton, M.S.; Yakubu, R.; Han, B.; Tu, V.; Kato, K.; Kawazu, S.; et al. Toxoplasma gondii cyclic AMP-Dependent protein kinase subunit 3 Is Involved in the switch from tachyzoite to bradyzoite development. mBio 2016, 7. [CrossRef] [PubMed]

43. Agop-Nersesian, C.; Naissant, B.; Ben Rached, F.; Rauch, M.; Kretzschmar, A.; Thiberge, S.; Menard, R.; Ferguson, D.J.; Meissner, M.; Langsley, G. Rab11A-controlled assembly of the inner membrane complex is required for completion of apicomplexan cytokinesis. PLoS Pathog. 2009, 5, e1000270. [CrossRef] [PubMed]

44. Deitsch, K.W.; Dzikowski, R. Variant gene expression and antigenic variation by malaria parasites. Annu. Rev. Microbiol. 2017, 71, 625-641. [CrossRef] [PubMed] 
45. McCulloch, R.; Cobbold, C.A.; Figueiredo, L.; Jackson, A.; Morrison, L.J.; Mugnier, M.R.; Papavasiliou, N.; Schnaufer, A.; Matthews, K. Emerging challenges in understanding trypanosome antigenic variation. Emerg. Top. Life Sci. 2017, 1, 585-592. [CrossRef] [PubMed]

46. Borst, P. Antigenic variation and allelic exclusion. Cell 2002, 109, 5-8. [CrossRef]

47. Gargantini, P.R.; Serradell, M.D.C.; Rios, D.N.; Tenaglia, A.H.; Lujan, H.D. Antigenic variation in the intestinal parasite Giardia lamblia. Curr. Opin. Microbiol. 2016, 32, 52-58. [CrossRef]

48. Lindsay, D.S.; Rippey, N.S.; Toivio-Kinnucan, M.A.; Blagburn, B.L. Ultrastructural effects of diclazuril against Toxoplasma gondii and investigation of a diclazuril-resistant mutant. J. Parasitol. 1995, 81, 459-466. [CrossRef]

49. Stock, M.; Elazab, S.; Hsu, W. Review of triazine anti-protozoal drugs used in veterinary medicine. J. Vet. Pharmacol. Ther. 2017, 41, 184-194. [CrossRef]

(C) 2020 by the authors. Licensee MDPI, Basel, Switzerland. This article is an open access article distributed under the terms and conditions of the Creative Commons Attribution (CC BY) license (http://creativecommons.org/licenses/by/4.0/). 